\title{
Prognostic significance of Dicer expression in hepatocellular carcinoma
}

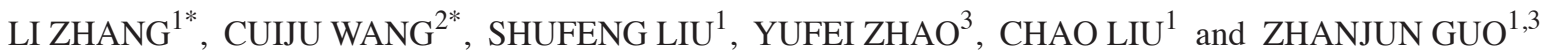 \\ ${ }^{1}$ Hebei Key Lab of Animal Science, Hebei Medical University, Shijiazhuang, \\ Hebei 050017; Departments of ${ }^{2}$ Gynecology Ultrasound and ${ }^{3}$ Gastroenterology and Hepatology, \\ The Fourth Hospital of Hebei Medical University, Shijiazhuang, Hebei 050011, P.R. China
}

Received March 18, 2015; Accepted April 5, 2016

DOI: $10.3892 / \mathrm{ol} .2016 .4547$

\begin{abstract}
Dicer is a RNaseIII endonuclease of the microRNA processing pathway, which is implicated in carcinogenesis of various types of human cancer. The present study assessed the expression level of Dicer in hepatocellular carcinoma (HCC) tissue to evaluate its association with HCC tumorigenesis. A low expression of Dicer was significantly associated with a shorter postoperative survival time of patients with HCC, which was assessed using the log-rank test with Kaplan-Meier survival analysis. Multivariate analysis identified that Dicer expression was an independent predictor for HCC outcome (relative risk, 0.660; 95\% confidence interval, 0.506-0.861; $\mathrm{P}=0.002)$. A functional assay demonstrated that Dicer overexpression inhibited the proliferation and promoted the apoptosis of HCC cells. In addition, a Transwell assay revealed that Dicer markedly inhibited the migration and invasion of HCC cells. The present findings indicate that Dicer expression modified the outcomes of HCC patients by inhibiting proliferation, promoting apoptosis and inhibiting metastasis of HCC cells.
\end{abstract}

\section{Introduction}

Hepatocellular carcinoma (HCC) is the fifth most common cancer worldwide and causes more than half a million mortalities each year, making it the third most common cause of cancer-associated mortality (1). Numerous prognostic factors, including tumor size, tumor quantity, cell differentiation, venous invasion, degree of inflammation and deregulated microRNAs (miRNA), have been identified for the recurrence

Correspondence to: Professor Zhanjun Guo, Department of Gastroenterology and Hepatology, The Fourth Hospital of Hebei Medical University, 12 Jiankang Road, Shijiazhuang, Hebei 050011, P.R. China

E-mail: zjguo5886@aliyun.com

*Contributed equally

Key words: Dicer, hepatocellular carcinoma, microRNA, proliferation, apoptosis, metastasis of HCC, but the molecular mechanism of HCC carcinogenesis is not fully understood (2-5). In addition, emerging evidence suggests that components of the RNA interference pathway and miRNAs may be important in the carcinogenesis of HCC (6).

miRNAs are small noncoding RNAs, 18-25 nucleotides in length, which bind to the 3'-untranslated region of target mRNAs. This sequence-specific binding leads to target mRNA degradation or repression, resulting in decreased levels of encoded protein $(7,8)$. miRNAs have already been implicated as regulators of numerous physiological and pathological processes, including development, cell proliferation, differentiation and apoptosis, and tumor progression and metastasis (9). Dicer is a cytoplasmic RNaseIII enzyme that cleaves the loop of pri-miRNA and long double-stranded RNA into $22 \mathrm{bp}$ double-stranded miRNAs and short interfering RNAs. It is associated with the regulation of cell proliferation and control of apoptosis $(10,11)$. Increasing evidence has demonstrated that there is a low expression of Dicer in tumors, including breast, lung and ovarian cancer, neuroblastoma, human tongue squamous cell carcinoma, chronic lymphocytic leukemia and nasopharyngeal carcinoma, and that it is associated with a poor prognosis as a tumor suppressor (12-23). mRNA levels of Dicer have been reported to be significantly downregulated in non-viral HCC patients and this has predicted the outcome of patients with $\mathrm{HCC}$ in previous studies $(24,25)$. The present study assessed the protein expression levels of Dicer in HCC patients, the majority of whom had viral HCC, and evaluate its association with HCC outcome.

\section{Materials and methods}

Tissue specimens. HCC tissues were obtained from 119 patients that underwent HCC resection at The Fourth Hospital of Hebei Medical University (Shijiazhuang, China) between March 2007 and September 2009. None of the patients had received chemotherapy prior to surgery. Adjacent non-tumor tissues were used as normal tissues for comparison to the HCC tissues. Tumor differentiation and pathological tumor stage were defined by the Edmondson grading system and the tumor-node-metastasis (TNM) classification of the International Union Against Cancer (26). The procedures of the present study were supervised and approved by the Human 

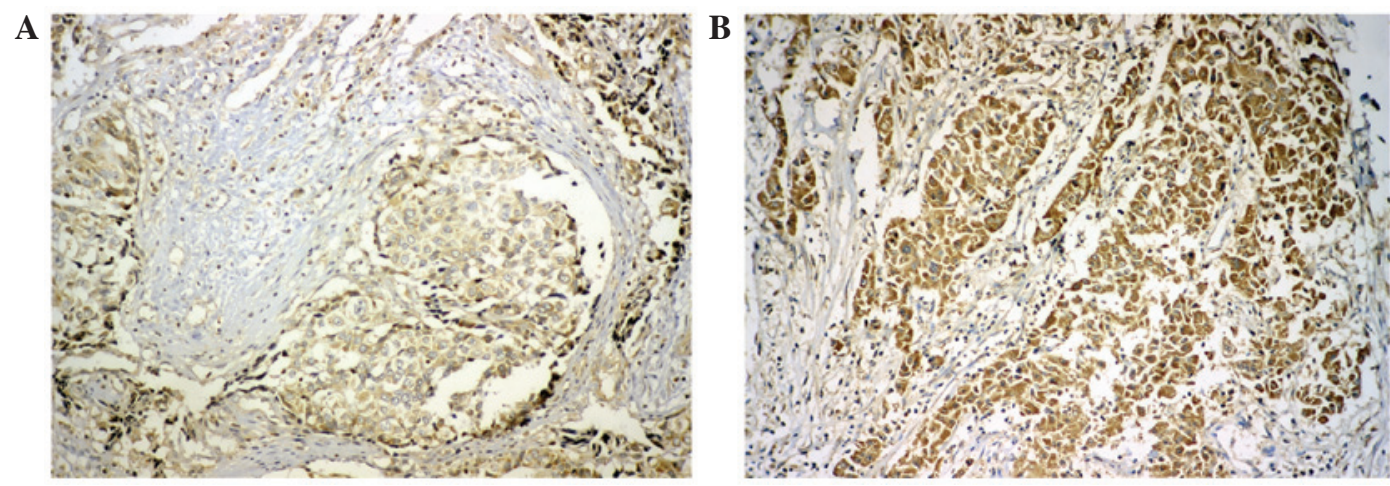

Figure 1. Dicer immunostaining in hepatocellular carcinoma tissues with (A) low expression and (B) high expression. Cells with a brown-stained cytoplasm are regarded as positive for Dicer expression. Magnification, $\mathrm{x} 400$.

Tissue Research Committee of The Fourth Hospital of Hebei Medical University (approval no., 2007MEC-005), and written informed consent was obtained from all the patients.

Immunohistochemistry. Serial tissue sections ( $4 \mu \mathrm{m}$ thick) were deparaffinized with xylene, rehydrated, and subjected to microwave antigen retrieval in citrate buffer $(\mathrm{pH}, 6.0)$ for $20 \mathrm{~min}$. Subsequently, 3\% hydrogen peroxide (Invitrogen ${ }^{\mathrm{TM}}$; Thermo Fisher Scientific, Inc., Waltham, MA, USA) in methanol was used to quench endogenous peroxidase activity, followed by incubation with $1 \%$ bovine serum albumin $\left(\right.$ Pierce $^{\mathrm{TM}}$; Thermo Fisher Scientific, Inc.) to block nonspecific binding. Sections were incubated with rabbit polyclonal anti-DICER (catalog no., ab93380; dilution, 1:100; Abcam, Cambridge, UK) overnight at $4^{\circ} \mathrm{C}$. Subsequent to rinsing with phosphate buffer $(\mathrm{pH}, 7.2)$ three times, the slides were incubated with biotinylated secondary anti-rabbit IgG antibody for $20 \mathrm{~min}$ at room temperature and stained with 3,3'-diaminobenzidine (catalog no., kit-0017; Maixin Biotechnology Development, Co., Ltd., Fuzhou, China), according to the manufacturer's protocol. All the slides were counterstained with hematoxylin (Beijing Zhongshan Golden Bridge Biotechnology Co., Beijing, China), dehydrated and mounted with a coverslip using a standard medium. The slides were visualized using the Leica DM IL inverted microscope (Leica Microsystems GmbH, Wetzlar, Germany). Two independent pathologists, who were blinded to the study design, were employed to review the results and score all samples, using the HSCORE as described previously $(17,27)$. The staining intensity was scored as follows: 0 , no staining; 1 , weak staining, light-yellow; 2 , moderate-weak staining, yellow brown; 3, moderate-strong staining, brown; and 4 , strong staining, dark brown). The HSCORE represents the sum of each of the percentages multiplied by the weighted intensity of staining as follows: HSCORE $=(i+1) \pi$, where $\mathrm{i}=1,2,3$ and 4 , and $\pi$ varies between 0 and $100 \%$. A score of $>100$ was defined as high expression and $\leq 100$ as low expression (Fig. 1).

Cell culture and transfection. Human hepatocellular carcinoma HepG2 cell line was purchased from the Cell Resource Center, Institute of Basic Medical Sciences, Chinese Academy of Medical Sciences (Beijing, China). The cells were maintained as an adherent cell line in Dulbecco's modified Eagle's medium (DMEM; Gibco ${ }^{\circledR}$; Thermo Fisher
Scientific, Inc.) supplemented with $10 \%$ fetal bovine serum (Invitrogen $^{\mathrm{TM}}$; Thermo Fisher Scientific, Inc.), 1X MEM Non-Essential Amino Acid, 2 mmol/l L-glutamine, $50 \mathrm{U} / \mathrm{ml}$ penicillin and $50 \mu \mathrm{g} / \mathrm{ml}$ streptomycin (all Gibco ${ }^{\circledR}$; Thermo Fisher Scientific, Inc.) in a humidified atmosphere of $5 \% \mathrm{CO}_{2}$ at $37^{\circ} \mathrm{C}$. The pcDNA3.1-Dicer vector was a kindly donated by Professor Zhihong Zheng (China Medical University, Taichung, Taiwan). The HepG2 cells were transfected with pcDNA3.1 (+) (Invitrogen ${ }^{\mathrm{TM}}$; Thermo Fisher Scientific, Inc.) and pcDNA3.1 (+)-Dicer plasmids using Lipofectamine ${ }^{\circledR} 2000$ (Invitrogen $^{\mathrm{TM}}$; Thermo Fisher Scientific, Inc.), which contained geneticin selective markers. Stable cells were harvested 8 weeks later using geneticin selection, and the results are represented as PC-control and PC-Dicer.

Cell proliferation. Cell proliferation capacity was analyzed by Cell Counting kit-8 (CCK-8; Dojindo Molecular Technologies, Inc., Kumamoto, Japan) as described previously (28). Briefly, the cells were seeded into 96-well plates (Corning Incorporated, Corning, NY, USA) at a density of $10^{3}$ cells/well and incubated for 1-7 days under the conditions stated previously. In total, $10 \mu \mathrm{l}$ CCK- 8 was added to each well, according to manufacturer's protocol, followed by incubation at $37^{\circ} \mathrm{C}$ with $5 \%$ humidified $\mathrm{CO}_{2}$ for $2 \mathrm{~h}$. The absorbance of the cells was measured at $450 \mathrm{~nm}$ with Thermo Multiskan ${ }^{\mathrm{TM}}$ Spectrum microplate reader (Thermo Fisher Scientific, Inc. CCK-8 allows sensitive colorimetric assays for the determination of cell proliferation by measuring dehydrogenases in viable cells. All assays were carried out independently three times.

Cell migration and invasion assay. Stably transfected cells were harvested and resuspended in medium without fetal bovine serum and subsequently placed in the top chamber of a 24-well Transwell plate with $8 \mu \mathrm{m}$ pore size (Costar Inc., Milpitas, CA, USA) at a density of $1 \times 10^{5}$ cells/well. The lower chamber was filled with media supplemented with $10 \%$ fetal bovine serum. After $48 \mathrm{~h}$, unmigrated cells were removed from the upper surface of the Transwell membrane using a cotton-tipped swab, and the migrated cells on the lower membrane surface were fixed with $90 \%$ alcohol and then stained with $0.05 \%$ crystal violet (Nanjing Chemical Technology Co., Ltd., Nanjing, China). The invasion assay was performed in the same way, with the exception that the membrane insert was coated with Matrigel (BD Biosciences, Franklin Lakes, NJ, USA) diluted 
Table I. Univariate analysis of clinical characteristics associated with postoperative survival in patients with hepatocellular carcinoma.

\begin{tabular}{|c|c|c|c|}
\hline Characteristic & $\mathrm{n}$ & $\begin{array}{c}\text { 3-year survival } \\
\text { rate, } \%\end{array}$ & P-value \\
\hline Total & 119 & & \\
\hline Gender & & & 0.269 \\
\hline Male & 106 & 47.2 & \\
\hline Female & 13 & 61.5 & \\
\hline Age, years & & & 0.485 \\
\hline$\leq 55$ & 61 & 45.9 & \\
\hline$>55$ & 58 & 51.7 & \\
\hline Tumor size, cm & & & $<0.010$ \\
\hline$\leq 5$ & 52 & 69.2 & \\
\hline$>5$ & 67 & 32.8 & \\
\hline Tumor quantity & & & 0.468 \\
\hline Single & 96 & 50.0 & \\
\hline Multiple & 23 & 43.5 & \\
\hline Child classification & & & 0.258 \\
\hline A & 110 & 50.0 & \\
\hline B & 9 & 33.3 & \\
\hline TNM classification & & & $<0.010$ \\
\hline I & 43 & 74.4 & \\
\hline II & 70 & 35.7 & \\
\hline III & 6 & 16.7 & \\
\hline Portal vein thrombosis & & & $<0.010$ \\
\hline Yes & 16 & 6.3 & \\
\hline No & 103 & 55.3 & \\
\hline Dicer expression & & & $<0.010$ \\
\hline High & 66 & 63.6 & \\
\hline Low & 53 & 30.2 & \\
\hline
\end{tabular}

Tumor size was measured by diameter. Statistical analysis was calculated using the log-rank test. TNM, tumor-node-metastasis.

in DMEM (dilution, 1:4). The migrated/invading cells were randomly counted under a Leica DM IL inverted microscope in 5 representative areas on each plate (magnification, $x 200$ ). The data are presented as the mean \pm standard error of the mean from at least three independent experiments.

Terminal deoxynucleotidyl transferase dUTP nick-end labeling (TUNEL) assay. Cell apoptosis was detected using 4',6-diamidino-2-phenylindole dihydrochloride (DAPI; Solarbio Science and Technology Co., Ltd., Beijing, China) staining and TUNEL assay. TUNEL assays were performed using the In Situ Cell Death Detection kit (Roche Diagnostics, Basel, Switzerland), according to manufacturer's protocol. The cells were fixed in $4 \%$ paraformaldehyde (Nanjing Chemical Technology Co., Ltd.) at room temperature for $1 \mathrm{~h}$, penetrated with $0.5 \%$ Triton X-100 (Amresco LLC, Solon, OH, USA) for $2 \mathrm{~min}$ on ice and then incubated with TUNEL reaction mixture for $1 \mathrm{~h}$ at $37^{\circ} \mathrm{C}$. Positive fluorescence was detected
Table II. Multivariate analysis of prognostic factors associated with postoperative survival in patients with hepatocellular carcinoma.

\begin{tabular}{|c|c|c|c|}
\hline Characteristic & RR & $95 \% \mathrm{CI}$ & P-value \\
\hline Tumor size, $\leq 5$ vs. $>5 \mathrm{~cm}$ & 2.608 & $1.429-4.760$ & 0.002 \\
\hline TNM, I vs. II vs. III & 1.781 & $0.678-4.682$ & 0.242 \\
\hline PVT, yes vs. no & 2.870 & $1.552-5.307$ & 0.001 \\
\hline Dicer expression, igh vs. low & 0.660 & $0.506-0.861$ & 0.002 \\
\hline Gender, male vs. female & 2.612 & $1.008-6.772$ & 0.048 \\
\hline Age, $\leq 55$ vs. $>55$ years & 0.744 & $0.439-1.260$ & 0.271 \\
\hline Tumors, single vs. multiple & 2.870 & $1.552-5.307$ & 0.001 \\
\hline Child classification, A vs. B & 1.560 & $0.640-3.803$ & 0.328 \\
\hline
\end{tabular}

Statistical analysis calculated using Cox proportional hazards model. TNM, tumor-node-metastasis; PVT, portal vein thrombosis; RR, relative risk; $\mathrm{CI}$, confidence interval.

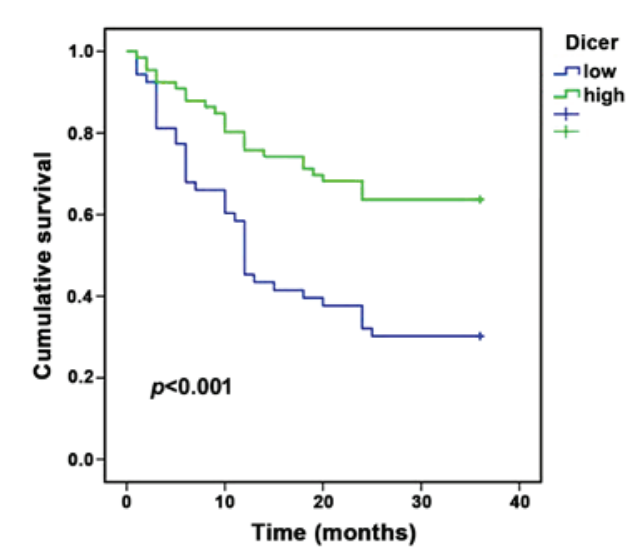

Figure 2. Survival curve analysis in hepatocellular carcinoma patients with high and low Dicer expression.

at an excitation wavelength in the range of 570-620 nm (maximum, $580 \mathrm{~nm}$; red) using a Leica DM IL inverted microscope. DAPI was excited with ultraviolet light. The experiment was repeated at least three times.

Western blot analysis. Protein was isolated from cells using RIPA buffer (Beyotime Institute of Biotechnology, Haimen, China), according to the manufacturer's instructions. The protein concentration was measured by performing a BCA assay. Total protein $(50 \mu \mathrm{g})$ was denatured by boiling for $5 \mathrm{~min}$ and was separated using $7 \%$ sodium dodecyl sulfate-polyacrylamide gel electrophoresis, then transferred onto a polyvinylidene difluoride membrane (Sigma-Aldrich, St. Louis, MO, USA). After blocking with 5\% skim milk for $2 \mathrm{~h}$, the membrane was incubated with primary antibody at $4^{\circ} \mathrm{C}$ overnight. Subsequently, the membrane was incubated with secondary antibody for $30 \mathrm{~min}$ at $37^{\circ} \mathrm{C}$ and washed by phosphate-buffered saline with Tween 20 . Western blot analysis was performed with rabbit polyclonal anti-Dicer (dilution, 1:1,000; catalog no., ab93380; Abcam), rabbit monoclonal anti-B-cell lymphoma 2 (Bcl-2; dilution, 1:500; catalog no., AB112; Beyotime Institute of Biotechnology), mouse 
A
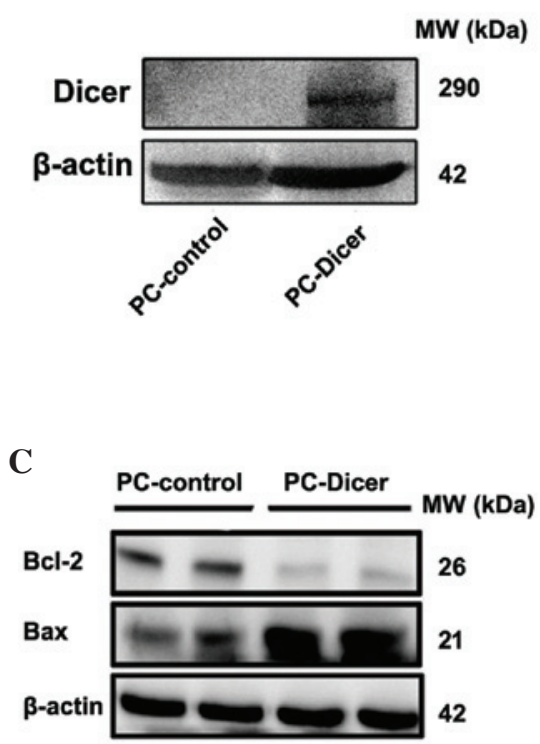

B

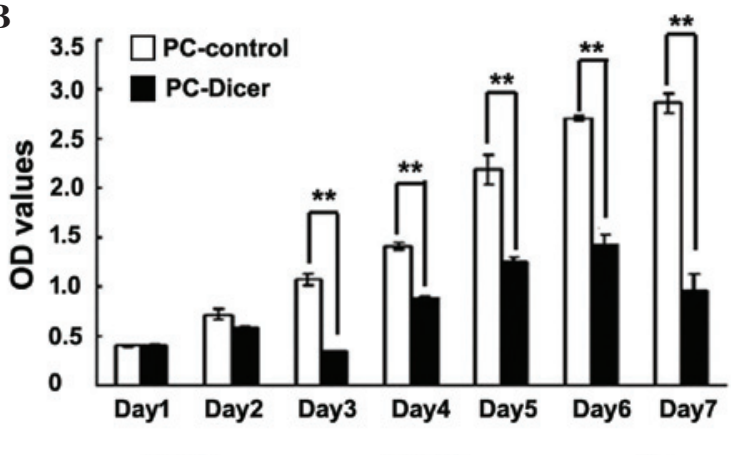

D

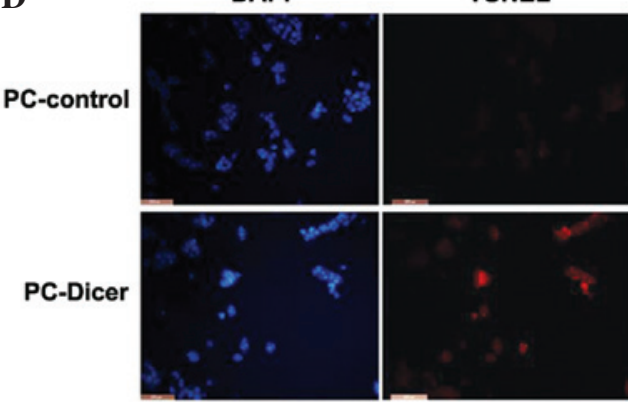

Merge

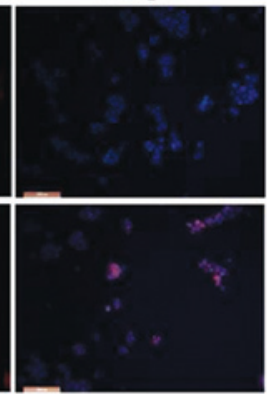

Figure 3. Dicer inhibits the proliferation and induces apoptosis in hepatocellular carcinoma HepG2 cells. (A) Identification of Dicer expression in PC-control and PC-Dicer transfected HepG2 cells. (B) Cell viability was measured using cell counting kit- 8 assay. Data are presented as the mean \pm standard error of the mean of three independent experiments. ${ }^{* *} \mathrm{P}<0.01$ vs. PC-control cells. (C) Protein expression of Bax and Bcl-2 was evaluated by western blot analysis. (D) Cell apoptosis was observed by TUNEL assay. HepG2 cells transfected with PC-control and PC-Dicer were stained with TUNEL and viewed under a fluorescence microscope (magnification, x200; scale bar, $200 \mu \mathrm{m}$ ). MW, molecular weight; Bcl-2, B-cell lymphoma 2; Bax, Bcl-2-like protein 4; DAPI, 4',6-diamidino-2-phenylindole dihydrochloride; TUNEL, terminal deoxynucleotidyl transferase dUTP nick-end labeling.

A

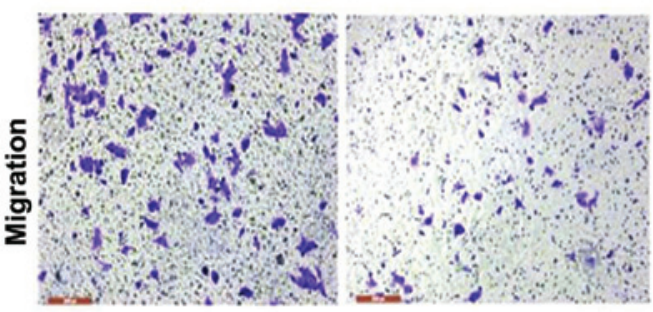

B

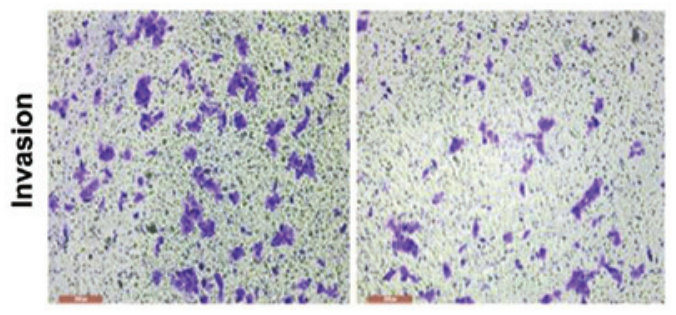

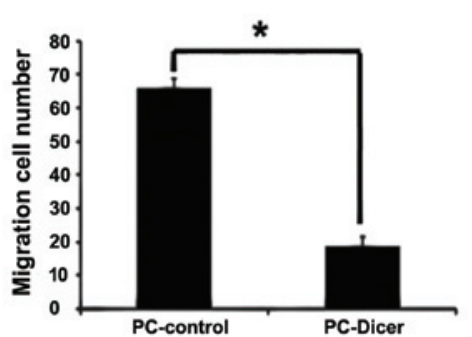

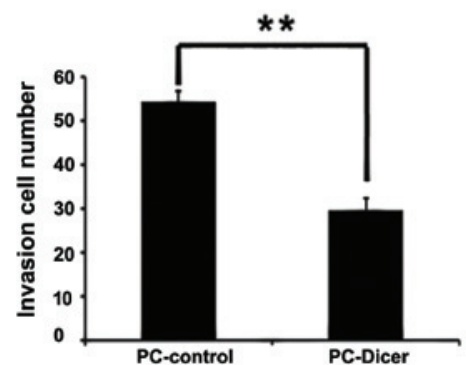

Figure 4. Suppressive effect of Dicer overexpression on the (A) migration and (B) invasion ability of heptocellular carinoma cells. " $\mathrm{P}<0.05$, ${ }^{* * *} \mathrm{P}<0.01 \mathrm{vs} . \mathrm{PC}-\mathrm{control}$ cells. Magnification, x200; scale bar, $200 \mu \mathrm{m}$.

monoclonal anti-Bcl-2-like protein 4 (Bax; dilution, 1:500; catalog no., AB026; Beyotime Institute of Biotechnology) and rabbit polyclonal anti- $\beta$-actin (dilution, 1:500; catalog no., sc-7210; Santa Cruz Biotechnology, Inc., Dallas, TX, USA) antibodies. An HRP-conjugated anti-rabbit IgG antibody was used as the secondary antibody (dilution, 1:2,000; catalog no., ZDR-5403; Beijing Zhongshan Golden Bridge Biotechnology Co.). Signals were detected using FluorChem ${ }^{\circledR}$ HD2 (Alpha Innotech Corporation, San Leandro, CA, USA).
Statistical analysis. Survival curves were calculated using the Kaplan-Meier method, and comparisons between the curves were made using the log-rank test. Multivariate survival analysis was performed using a Cox proportional hazards model. Data from the CCK-8, migration and invasion assay were compared using Student's t-test. A two-tailed value of $\mathrm{P}<0.05$ was considered to indicate a statistically significant difference. Statistical analysis was performed using SPSS version 15.0 software (SPSS, Inc., Chicago, IL, USA). 


\section{Results}

Clinical characteristics of patients with HCC. A total of 119 patients were enrolled in the present study, which consisted of 32 non-viral HCC patients, 82 hepatitis B (HBV)-associated $\mathrm{HCC}$ patients, 3 hepatitis $\mathrm{C}(\mathrm{HCV})$-associated $\mathrm{HCC}$ patients and $2 \mathrm{HCC}$ patients with $\mathrm{HCV}$ and HBV infections. The patients were followed up every 3 months for 3 years, using routin radiological and biochemical examination. Survival was measured between the day of surgery and the date of recurrence, metastasis and mortality. The association between the data collected during the 3-year follow-up and the patients' clinical characteristics was analyzed using the log-rank test with the Kaplan-Meier method. Gender, age, tumor quantity and child classification (Child-Pugh grade) (29) were not statistically significant predictors of postoperative survival time; however, tumor size, TNM classification and portal vein thrombosis were associated with survival time in these patients (Table I).

Dicer expression in HCC tissues, and its association with HCC survival. Dicer staining was observed in the cytoplasm of cells in immunohistochemically stained HCC tissues (Fig. 1). A reduced expression of Dicer (HSCORE 60) was observed in cancerous tissues compared with adjacent non-cancerous tissues (HSCORE 360). The patients with HCC were divided into two groups on the basis of Dicer expression levels: High expression, $n=66$; low expression, $n=53$. Postoperative survival curves were plotted using the Kaplan-Meier method for the high and low Dicer groups, and the results demonstrated that the 3-year survival rates of patients were $63.6 \%$ for the high expression group and $30.2 \%$ for the low expression group. Patients in the low Dicer expression group were associated with a shorter survival time compared with patients in the high Dicer expression group ( $\mathrm{P}<0.001$; Fig. 2).

Multivariate analysis was performed using Cox proportional hazards model for various predictive factors. As shown in Table II, Dicer expression was identified as an independent predictor of HCC outcome [relative risk (RR), 0.660; $95 \%$ confidence interval, $0.506-0.861 ; \mathrm{P}=0.002]$. Size of the tumor (RR, 2.608; 95\% CI, 1.429-4.760; $\mathrm{P}=0.002)$, portal vein thrombosis ( $\mathrm{RR}, 2.870 ; 95 \% \mathrm{CI}, 1.552-5.307 ; \mathrm{P}=0.001)$, gender (RR, 2.612; 95\% CI, 1.008-6.772; $\mathrm{P}=0.048)$ and tumor quantity (RR, 2.870; 95\% CI, 1.552-5.307; $\mathrm{P}=0.001)$ were also identified as independent predictive factors for HCC outcome. These data demonstrate that Dicer expression is a clear predictive factor for the outcome of HCC patients.

Dicer inhibits proliferation and induces apoptosis of HCC cells. A CCK-8 assay was performed to measure the proliferation capacity of the HepG2 cells. Cell viability in HepG2 cells overexpressing Dicer was significantly reduced compared with control cells between day 3 and 7 (Fig. 3A and B; day 1, $\mathrm{P}=0.077$; day $2, \mathrm{P}=0.068$; day $3, \mathrm{P}=0.001$; day $4, \mathrm{P}=0.004$; day $5, \mathrm{P}=0.008$; day $6, \mathrm{P}=0.002$; day $7, \mathrm{P}=0.001$ ). To elucidate the potential mechanisms of this growth inhibition by Dicer, expression of apoptosis-associated factors Bax and Bcl-2 were assessed using western blot analysis, and a TUNEL assay was performed. Protein levels of Bcl-2 were significantly reduced whereas Bax protein levels were markedly elevated in the
PC-Dicer HCC cells. The presence of TUNEL-positive cells (stained red) also revealed that DNA strand breaks occurred in HepG2 cells transfected with PC-Dicer (Fig. 3C and D). These data indicate that Dicer inhibits the proliferation and promotes the apoptosis of HCC cells.

Dicer overexpression suppressed the migration and invasion of HCC cells. As migration and invasion is an important factor for tumor metastasis, the effects of Dicer overexpression on cell migration and invasion was evaluated using Transwell assays. The results demonstrated that compared with the control cells, PC-Dicer stably transfected cells had significantly decreased migration $(\mathrm{P}<0.01)$ and invasion $(\mathrm{P}<0.05)$ capacities $($ Fig. 4). Overexpression of Dicer reduced the migration capacity of cells by $\sim 70 \%$ and invasive capacity by $\sim 45 \%$ in Dicer overexpressed HepG2 cells compared with control cells.

\section{Discussion}

A reduction of miRNA expression has been identified in various cancer models using miRNA expression profiling analyses, which has led to the generation of the hypothesis that miRNA processing machinery genes, including Dicer, are deregulated in tumor tissues (30). Low Dicer expression has been revealed to be associated with advanced tumor stages and poor clinical outcome in numerous types of cancer $(16-23,31,32)$. However, controversial data has been obtained in certain types of cancer; Dicer has been observed to be upregulated in prostate adenocarcinoma, ovarian serous carcinoma and colorectal cancer (33-36).

The present study evaluated the protein level of Dicer in HCC tissue to investigate its association with HCC tumorigenesis. Consistent with previous reports that demonstrated that there is reduced Dicer mRNA expression in nonviral HCC patients (25), the present study revealed that there were reduced Dicer protein levels in viral $\mathrm{HCC}$ patients, and that the expression of Dicer was associated with postoperative HCC survival as a tumor suppressor gene. The potential mechanism of Dicer in HCC may be explained to a certain degree by the present functional assay data, which indicated that Dicer inhibited the proliferation, migration and invasion and promoted the apoptosis of HCC cells. The present data corroborates previous observations that Dicer C-terminal fragment possesses DNase activity that is critical for DNA fragmentation during apoptosis (37).

A previous study using a miRNA microarray was performed to identify candidate miRNAs regulated by Dicer using a small HCC sample size (38). That study demonstrated that the miRNA expression profiling was downregulated in tissues that had a low expression of Dicer. Proliferative and apoptotic (mitogen-activated protein kinases and Wnt), adhesive (cell adhesion molecules and adherens junction) and survival (ErbB) signaling pathways appeared to be involved in HCC tumorigenesis through Dicer mediation (data not shown). Angiogenesis is a novel target for cancer therapy; however, the expression of the angiogenesis associated factors vascular endothelial growth factor and E-cadherin in HepG2 cells were not altered during Dicer overexpression (39).

In conclusion, the present study demonstrated that Dicer is important in HCC progression by mediating the proliferation, 
apoptosis and metastasis of HCC cells. Therefore, additional study to understand the mechanism of Dicer in HCC is crucial in the development of novel methods for the diagnosis and prognosis of this disease.

\section{Acknowledgements}

The present study was supported by Key Basic Research Program of Hebei (grant nos. 14967713D and 13967607D).

\section{References}

1. Gomaa AI, Khan SA, Toledano MB, Waked I and Taylor-Robinson SD: Hepatocellular carcinoma: Epidemiology, risk factors and pathogenesis. World J Gastroenterol 14: 4300-4308, 2008.

2. Guo Z, Wu C, Wang X, Wang C, Zhang R and Shan B: A polymorphism at the miR-502 binding site in the 3'-untranslated region of the histone methyltransferase SET8 is associated with hepatocellular carcinoma outcome. Int J Cancer 131: 1318-1322, 2012.

3. Guo Z, Li LQ, Jiang JH, Ou C, Zeng LX and Xiang BD: Cancer stem cell markers correlate with early recurrence and survival in hepatocellular carcinoma. World J Gastroenterol 20: 2098-2106, 2014.

4. Li X, Yang W, Lou L, Chen Y, Wu S and Ding G: MicroRNA: A promising diagnostic biomarker and therapeutic target for hepatocellular carcinoma. Dig Dis Sci 59: 1099-1107, 2014.

5. Minagawa M, Makuuchi M, Takayama T and Kokudo N: Selection criteria for repeat hepatectomy in patients with recurrent hepatocellular carcinoma. Ann Surg 238: 703-710, 2003.

6. Callegari E, Gramantieri L, Domenicali M, D'Abundo L, Sabbioni S and Negrini M: MicroRNAs in liver cancer: A mode for investigating pathogenesis and novel therapeutic approaches. Cell Death Differ 22: 46-57, 2015.

7. Lee RC, Feinbaum RL and Ambros V: The C. elegans heterochronic gene lin-4 encodes small RNAs with antisense complementarity to lin-14. Cell 75: 843-854, 1993.

8. Bagga S, Bracht J, Hunter S, Massirer K, Holtz J, Eachus R and Pasquinelli AE: Regulation by let-7 and lin- 4 miRNAs results in target mRNA degradation. Cell 122: 553-563, 2005.

9. Bartel DP: MicroRNAs: Genomics, biogenesis, mechanism and function. Cell 116: 281-297, 2004.

10. Kuehbacher A, Urbich C, Zeiher AM and Dimmeler S: Role of Dicer and Drosha for endothelial microRNA expression and angiogenesis. Circ Res 101: 59-68, 2007.

11. Barbato C, Ciotti MT, Serafino A, Calissano P and Cogoni C: Dicer expression and localization in post-mitotic neurons. Brain Res 1175: 17-27, 2007.

12. Cochrane DR, Cittelly DM, Howe EN, Spoelstra NS McKinsey EL, LaPara K, Elias A, Yee D and Richer JK: MicroRNAs link estrogen receptor alpha status and Dicer levels in breast cancer. Horm Cancer 1: 306-319, 2010.

13. Dedes KJ, Natrajan R, Lambros MB, Geyer FC, Lopez-Garcia MA, Savage K, Jones RL and Reis-Filho JS: Down-regulation of the miRNA master regulators Drosha and Dicer is associated with specific subgroups of breast cancer. Eur J Cancer 47: 138-150, 2011

14. Yan M, Huang HY, Wang T, Wan Y, Cui SD, Liu ZZ and Fan QX Dysregulated expression of Dicer and drosha in breast cancer. Pathol Oncol Res 18: 343-348, 2012.

15. Caffrey E, Ingoldsby H, Wall D, Webber M, Dinneen $\mathrm{K}$, Murillo LS, Inderhaug C, Newell J, Gupta S and Callagy G: Prognostic significance of deregulated Dicer expression in breast cancer. PLoS One 8: e83724, 2013.

16. Karube Y, Tanaka H, Osada H, Tomida S, Tatematsu Y, Yanagisawa K, Yatabe Y, Takamizawa J, Miyoshi S, Mitsudomi T and Takahashi T: Reduced expression of Dicer associated with poor prognosis in lung cancer patients. Cancer Sci 96: 111-115, 2005.

17. Merritt WM, Lin YG, Han LY, Kamat AA, Spannuth WA, Schmandt R, Urbauer D, Pennacchio LA, Cheng JF, Nick AM, et al: Dicer, Drosha, and outcomes in patients with ovarian cancer. N Engl J Med 359: 2641-2650, 2008.

18. Köbel M, Gilks CB and Huntsman DG: Dicer and Drosha in ovarian cancer. N Engl J Med 360: 1150-1151; author reply 1151, 2009.
19. Pampalakis G, Diamandis EP, Katsaros D and Sotiropoulou G: Down-regulation of Dicer expression in ovarian cancer tissues. Clin Biochem 43: 324-327, 2010.

20. Lin RJ, Lin YC, Chen J, Kuo HH, Chen YY, Diccianni MB, London WB, Chang $\mathrm{CH}$ and $\mathrm{Yu}$ AL: MicroRNA signature and expression of Dicer and Drosha can predict prognosis and delineate risk groups in neuroblastoma. Cancer Res 70: 7841-7850, 2010.

21. Zeng S, Yang J, Zhao J, Liu Q, Rong M, Guo Z and Gao W: Silencing Dicer expression enhances cellular proliferative and invasive capacities in human tongue squamous cell carcinoma. Oncol Rep 31: 867-873, 2014.

22. Zhu DX, Fan L, Lu RN, Fang C, Shen WY, Zou ZJ, Wang YH, Zhu HY, Miao KR, Liu P, et al: Downregulated Dicer expression predicts poor prognosis in chronic lymphocytic leukemia. Cancer Sci 103: 875-881, 2012.

23. Guo X, Liao Q, Chen P, Li X, Xiong W, Ma J, Li X, Luo Z, Tang H, Deng M, et al: The microRNA-processing enzymes: Drosha and Dicer can predict prognosis of nasopharyngeal carcinoma. J Cancer Res Clin Oncol 138: 49-56, 2012.

24. Wu JF, Shen W, Liu NZ, Zeng GL, Yang M, Zuo GQ, Gan XN, Ren H and Tang KF: Down-regulation of Dicer in hepatocellular carcinoma. Med Oncol 28: 804-809, 2011.

25. Kitagawa N, Ojima H, Shirakihara T, Shimizu H, Kokubu A, Urushidate T, Totoki Y, Kosuge T, Miyagawa S and Shibata T: Downregulation of the microRNA biogenesis components and its association with poor prognosis in hepatocellular carcinoma. Cancer Sci 104: 543-551, 2013.

26. Edge SB, Byrd DR and Compton CC: The American Joint Committee on Cancer: The 7th edition of the AJCC cancer staging manual and the future of TNM. Ann Surg Oncol 17: 1471-1474, 2010

27. Singh M, Zaino RJ, Filiaci VJ and Leslie KK: Relationship of estrogen and progesterone receptors to clinical outcome in metastatic endometrial carcinoma: A Gynecologic oncology group study. Gynecol Oncol 106: 325-333, 2007.

28. Yang $M$ and Zhou $H$ : Grass carp transforming growth factor-beta 1 (TGF-beta 1): Molecular cloning, tissue distribution and immunobiological activity in teleost peripheral blood lymphocytes. Mol Immunol 45: 1792-1798, 2008.

29. Pugh RN, Murray-Lyon IM, Dawson JL, Pietroni MC and Williams R: Transection of the oesophagus for bleeding oesophageal varices. Br J Surg 60: 646-649, 1973.

30. Lu J, Getz G, Miska EA, Alvarez-Saavedra E, Lamb J, Peck D, Sweet-Cordero A, Ebert BL, Mak RH, Ferrando AA, et al: MicroRNA expression profiles classify human cancers. Nature 435: 834-838, 2005.

31. Jafarnejad SM, Ardekani GS, Ghaffari M, Martinka M and Li G: Sox4-mediated Dicer expression is critical for suppression of melanoma cell invasion. Oncogene 32: 2131-2139, 2013.

32. Kuang Y, Cai J, Li D, Han Q, Cao J and Wang Z: Repression of Dicer is associated with invasive phenotype and chemoresistance in ovarian cancer. Oncol Lett 5: 1149-1154, 2013.

33. Bian XJ, Zhang GM, Gu CY, Cai Y, Wang CF, Shen YJ, Zhu Y, Zhang HL, Dai B and Ye DW: Down-regulation of Dicer and Ago2 is associated with cell proliferation and apoptosis in prostate cancer. Tumour Biol 35: 11571-11578, 2014.

34. Faber C, Horst D, Hlubek F and Kirchner T: Overexpression of Dicer predicts poor survival in colorectal cancer. Eur J Cancer 47: 1414-1419, 2011.

35. Faggad A, Budczies J, Tchernitsa O, Darb-Esfahani S, Sehouli J, Müller BM, Wirtz R, Chekerov R, Weichert W, Sinn B, et al: Prognostic significance of Dicer expression in ovarian cancer-link to global microRNA changes and oestrogen receptor expression. J Pathol 220: 382-391, 2010.

36. Gao C, Li X, Tong B, Wu K, Liu Y, Anniko M and Duan M: Up-regulated expression of Dicer reveals poor prognosis in laryngeal squamous cell carcinoma. Acta Otolaryngol 134: 959-963, 2014.

37. Nakagawa A, Shi Y, Kage-Nakadai E, Mitani S and Xue D: Caspase-dependent conversion of Dicer ribonuclease into a death-promoting deoxyribonuclease. Science 328: 327-334, 2010.

38. Krill KT, Gurdziel K, Heaton JH, Simon DP and Hammer GD: Dicer deficiency reveals microRNAs predicted to control gene expression in the developing adrenal cortex. Mol Endocrinol 27: 754-768, 2013

39. Wu YY, Chen L, Wang GL, Zhang YX, Zhou JM, He S, Qin J and Zhu YY: Inhibition of hepatocellular carcinoma growth and angiogenesis by dual silencing of NET-1 and VEGF. J Mol Histol 44: 433-445, 2013 